\title{
Measuring Spatial and Vertical Heterogeneity of Grasslands Using Remote Sensing Techniques
}

\author{
X. Guo ${ }^{1 *}$, J. Wilmshurst ${ }^{2}$, S. McCanny ${ }^{3}$, P. Fargey ${ }^{4}$ and P. Richard ${ }^{5}$ \\ ${ }^{1}$ University of Saskatchewan, 9 Campus Drive, Saskatoon, Saskatchewan S7N 5A5, Canada \\ ${ }^{2}$ Parks Canada, 145 McDermot Ave., Winnipeg, Manitoba R3B 0R9, Canada \\ ${ }^{3}$ Parks Canada, 25 Eddy St., Hull, Quebec K1A 0M5, Canada \\ ${ }^{4}$ Grasslands National Park, Box 150, Val Marie, Saskatchewan S0N 2T0, Canada \\ ${ }^{5}$ University of Sherbrooke, Sherbrooke, Quebec J1K 2R1, Canada
}

\begin{abstract}
Grassland heterogeneity, defined by its components of spatial pattern, vertical structure, and species composition, is one of the most important indicators of prairie habitat. Maintaining grassland under conservation without disturbance may result in homogeneity at multiple spatial scales that could reduce wildlife diversity as a consequence. Therefore, monitoring grassland conditions that contribute to diversity can be critical for wildlife habitat and ecological integrity. Remote sensing, with multi-spatial, multi-spectral, and multi-temporal resolutions plus newly developed analytical techniques, provides a potential tool for measuring grassland heterogeneity under different management regimes quickly, efficiently, and at low cost. The objectives of this study were 1) to evaluate the heterogeneity of grassland under grazing and conservation management practices spatially and vertically, and 2) to investigate the feasibility of using remotely sensed data to measure grassland heterogeneity. The study area was Grasslands National Park of Canada and its surrounding pastures. Field data were collected in the 1999 growing season by measuring the grassland vertical profile in a fixed spatial array. A Landsat Enhanced Thematic Mapper Plus (ETM+) image was acquired for the same year. A grey level co-occurrence matrix (GLCM) texture analysis was applied to the Landsat ETM+ imagery to compare the grasslands under grazing and those under the conservation practice. The results derived from field measurement show that the variation of vertical structures of grasslands differ significantly under grazing and conservation management regimes. Optical remote sensing data could detect the spatial variation of grasslands under these two management practices. Texture analysis is effective at $15 \mathrm{~m}$ resolution, which confirmed other studies that grassland heterogeneity is at about 15 meter.
\end{abstract}

Keywords: Digital image, grassland, remote sensing, spatial heterogeneity, species diversity, vertical structure

\section{Introduction}

Native prairie, the most endangered habitat in North America, has experienced dramatic species decline as a result of the conversion of native prairie to cropland (Tilman, 1999; Gauthier \& Wiken, 2003) and the introduction of exotic species (Mack, 1989). Even in remnant prairies, species, such as the Swift Fox (Smeeton \& Weagle, 2000), Burrowing Owl (Desmond et al., 2000), and Prairie Loggerhead Shrike (Cade $\&$ Woods, 1997), which are endemic to prairie grasslands, are decreasing significantly. This suggests that the quality of habitats is affecting populations, over and above the role of simple habitat loss. Understanding that many endangered prairie species have conflicting habitat requirements (Davis et al., 1999; Davis \& Duncan, 1999), land management should strive to create patchy vegetation structure to accommodate as many species as possible at a variety of spatial scales. Hence large patch heterogeneity caused by burning should be accompanied by small patch disturbances such as grazing. Further, vertical structure can be as important as spatial pat-

\footnotetext{
* Corresponding author: xulin.guo@usask.ca
}

terns. For example, in the semi-arid mixed grass prairie, some grassland songbirds select grassland habitats of different heights or amounts of standing dead grass (Davis et al., 1999; Davis \& Duncan, 1999).

Research has confirmed that disturbance, such as grazing, influences grassland heterogeneity dramatically (Collins \& Steinauer, 1998; Bai et al., 2001). Heterogeneity can increase or decrease depending on interactions between spatial patterns of grazing and vegetation (Adler et al., 2001), and it is highly influenced by precipitation since extremely dry conditions will exacerbate the effects of overgrazing.

Grassland heterogeneity, a dynamic indicator of grassland condition, composed of spatial pattern, vertical structure, and species composition, can be an indicator of wildlife habitat quality (Dennis et al., 1998) and should be monitored regularly. However, the difficulty of measuring grassland heterogeneity is a barrier given that field measurements are time consuming and often provide only point information. Remote sensing, a technique popularly used in forest structure and bird habitats (Imhoff et al., 1997), has limited application in prairie heterogeneity measurements because of the homogeneity of grasslands relative to forests at the resolution 
of most commonly used imagery. Existing studies of using remote sensing techniques on grassland structure mainly focus on vegetation cover and species differentiation. Goodin and Henebry (1997) at the Konza Prairie have successfully derived $\mathrm{C}_{3} / \mathrm{C}_{4}$ abundances using temporal trajectories of vegetation indices. Abundance of $\mathrm{C} 4$ species was also estimated by Davidson and Csillag (2003a) in the mixed grass prairie by comparing three approaches. Guo et al. (2000) have found that the forb component significantly influences the spectral characteristics of grasslands. Coefficient of variation (CV) and texture analysis have been broadly used for heterogeneity study as they are easy to compute and understand, especially for remotely sensed data (He et al. 1990; Hall-Beyer, 2000). Roth (1976) and Wiens (1974) applied CV as the heterogeneity index to measure spatial heterogeneity of grasslands at field level. Briggs and Nellis (1991) used textural algorithms to indicate landscape heterogeneity in a tallgrass prairie ecosystem. Jakubauskas (1997) used texture analysis to evaluate the heterogeneity of a forest ecosystem.

Based on the importance of both spatial pattern and vertical structure of grasslands for wildlife habitat, the objectives of this study were to compare the vertical and spatial variability of grasslands under grazing and conservation management practices, and to investigate the potential of remote sensing techniques for grassland heterogeneity measurement.

\section{Study Area}

This study was conducted in Grasslands National Park (GNP) of Canada and its surrounding rangeland, which is located in southern Saskatchewan along the international boundary of the United States and Canada (Figure 1). Characterized by a semi-arid mixed prairie ecosystem, this region has approximately $340 \mathrm{~mm}$ annual precipitation that mainly falls in the growing season (May - September) and a mean annual temperature of $3.4^{\circ} \mathrm{C}$ with the highest of $18.5^{\circ} \mathrm{C}$ in July and the lowest of $-13.6^{\circ} \mathrm{C}$ in January (Environment Canada, 2003). The park consists of two blocks, west and east, totaling approximately $906.5 \mathrm{~km}^{2}$. The initial efforts to establish a grassland national park can be traced back to 1956 as a recommendation from the Saskatchewan Natural History Society. In 1981, a legal agreement signed by Canada and Saskatchewan formally established the park. With the first land acquisition in 1984, some areas of the park have been under protection for almost 20 years. This means that there has been no grazing by large herbivores and active fire suppression. The land surrounding the park is either rotationally grazed or has been converted to crops. Because of the variation in management practices and the climate, this area provides an ideal study location to compare the grassland heterogeneity differences caused by grazing and conservation activities.

The current understanding of ecological integrity in Grasslands National Park suggests that some level of grazing disturbance may be necessary to maintain species diversity in a mixed prairie ecosystem. Therefore, a park management plan was approved in 2002 that included reintroduction of large animals at moderate and intensive grazing densities into the park (Parks Canada, 2002). To avoid unanticipated negative effects, and to justify activities, it is critical to develop a cost effective and expedient method to monitor the effects of planned disturbances in the park.

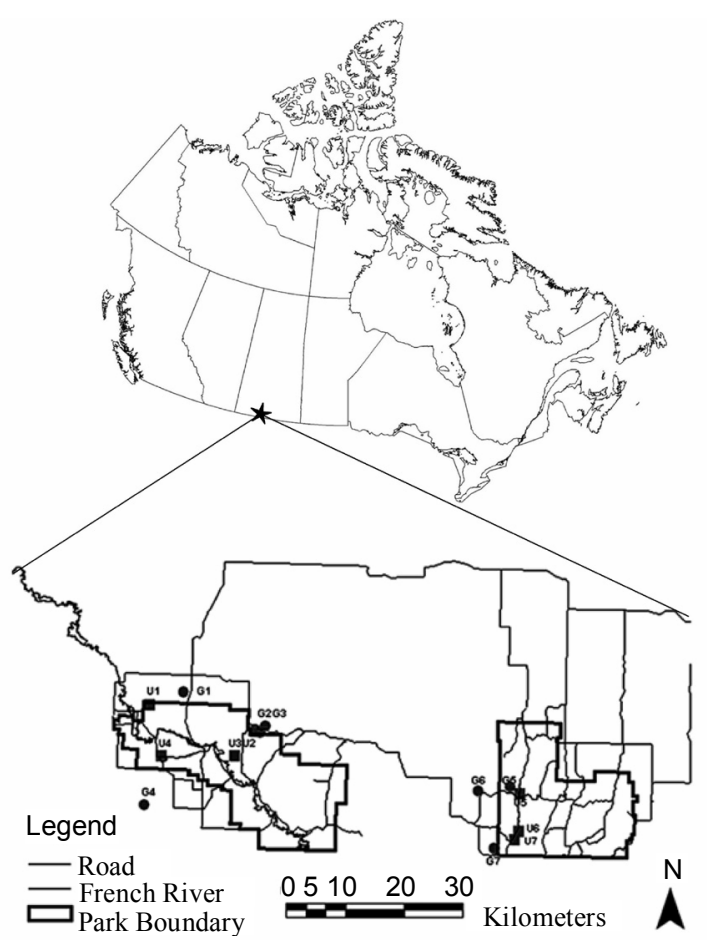

Figure 1. The study area: Grasslands National Park of Canada and surrounding pastures (sites were marked with $\mathrm{G}$ and $\mathrm{U}$ symbols with site numbers).

\section{Methods}

Seven pairs of grazed and conserved native prairie sites were identified by park managers as monitoring sites in the prairie upland within the park and the surrounding rangeland. Figure 1 shows the position of each site. Sites were matched primarily on the basis of soil texture and slope class, as well as soil $\mathrm{pH}$, acidity, and stoniness. At each site, five $100 \mathrm{~m}$, non-overlapping transects were surveyed from random starting points leading in random directions. The georeferenced coordinates for each base point and transact end were determined to within $3 \mathrm{~m}$ accuracy using a differentially corrected global positioning system technology (McCanny et al., 1996). Transect locations were permanently marked on the ground and the coordinates were digitized into the park's geographic information system database.

\subsection{Field Data Collection and Processing}

Heterogeneity sampling was conducted at four transects 
selected from the grazed and conserved sites in the summer of 1999. At the mid-point in each transect, sward structure was sampled in a cross-shaped pattern with one arm along the transect axis and one arm perpendicular to the transect. Samples were taken at 3 meter intervals starting at 1 meter from the intersection point. Nine samples in each direction extending to 25 meters were taken. Thus, 36 samples were collected for each transect and 72 for each management practice for a total of 144 samples.

At each sampling location, a $50 \mathrm{~cm} \times 1 \mathrm{~m}$ red board was set up vertically along with a scale bar marked in $1 \mathrm{~cm}$ intervals. Another board was laid down in front of the vertical red board $30 \mathrm{~cm}$ from its base to flatten vegetation between the camera and the $30 \mathrm{~cm}$ thick sward of grass being photographed. A digital camera with blue, green, and red channels was set up 1 meter away from the vertical red board. One picture was taken at each sampling location.

Based on the scale bar beside each picture, the maximum canopy height for each sample point was manually read within the digital picture. After experimenting with various ways of separating grasses and non-grasses from the image including values for each band, combinations of two bands and three bands, simple ratios, and vegetation indices, a normalized difference vegetation index (NDVI)-like index (NDVI-L) was selected, which was derived from the difference of red and green channels over the sum of these two for all images (Figure 2). Even though this index borrows the form of popular used NDVI, it uses different bands and is an empirical way of separating vegetation, which works for this image and cannot necessarily be extrapolated to other work. After all digital pictures were converted into NDVI-L images (with classified grass versus non-grass), a Visual Basic program was developed to interpret imagery to derive variables including canopy height and vegetation area ratio for each equal distance horizontally (e.g., $1 \mathrm{~cm}$ ). An area ratio between grasses and non-grasses was also calculated for any given vertical interval (e.g., $1 \mathrm{~cm})$.

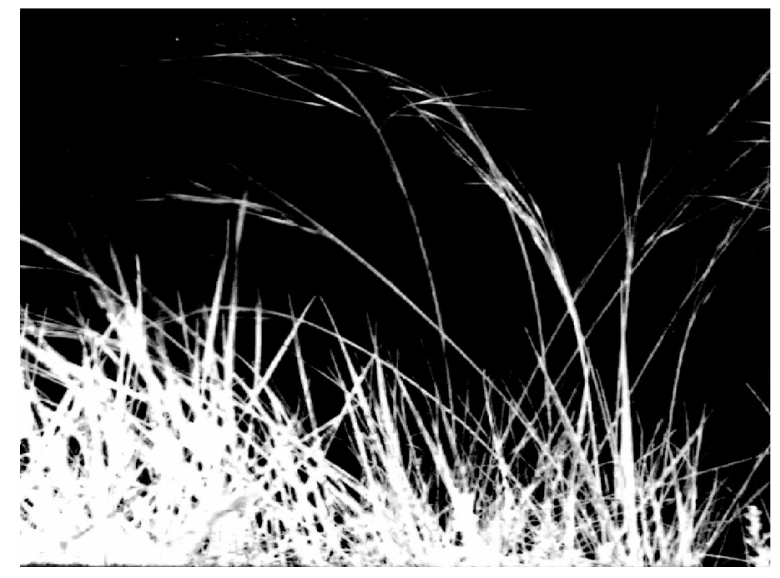

Figure 2. An NDVI-L imagery example (a ratio of the difference between green and red channels to the sum of them) derived from a digital picture.

\subsection{Remotely Sensed Data Acquisition and Processing}

One Landsat 7 Enhanced Thematic Mapper Plus (ETM+) image (Path 37, Row 26) was acquired for the study area, taken on August 23, 1999, about one month after the field data collection. The imagery was re-projected into UTM projection (zone 13). Based on the concern about the relief effects on values, the orthorectified imagery of the same scene was downloaded from the GeoGratis website (http:// geogratis.cgdi.gc.ca). A grey level co-occurrence matrix (GLCM) texture analysis procedure (Hall-Beyer, 2000) was applied to both images (with and without orthorectification) at 30 meter resolution for six optical bands (1-5 and 7) and the panchromatic band 8 with 15 meter resolution. Based on a previous study, $30 \mathrm{~m}$ resolution imagery was not significantly affected by window size on texture analysis, while larger winder sizes showed better results when a 15 meter resolution image was used for the texture analysis (Zhang et al., submitted). Therefore, in this study, we set the window size of $3 \times 3$ for the six $30 \mathrm{~m}$ resolution optical bands (1-5 and 7) to keep the minimum aggregation effects and the window size was set at $5 \times 5$ for the panchromatic band to cover a similar area with $30 \mathrm{~m}$ resolution bands for comparison purpose. Five $150 \mathrm{~m} \times 150 \mathrm{~m}$ areas were masked for each biosite (seven for grazed and seven for conserved sites). Polygons were at least two pixels away from the edge of the field and one pixel apart from other polygons. Any significant ponds were excluded during area selection. Raw digital numbers and variables derived from texture analysis were exported to a spreadsheet for further statistical analysis. By comparing values of these georectified and orthorectified images, all digital numbers of band 3 to band 7 were identical. The only difference exists in band 1 and band 2 with very high numbers in the orthorectified imagery. In the absence of an explanation of this problem, our analysis below was based on the imagery without othorectification, even though all analyses have been performed on both images. However, this whole procedure was simply to see if there is a topographical effect causing pixel displacement. Therefore, this is not surprising given these are upland sites apparently.

\subsection{Statistical Analyses}

In this study, the maximum canopy height derived from pictures for each sampling point was grouped into grazed and conserved grasslands. Basic statistics including mean, standard deviation, maximum, minimum, range and coefficient of variation $(\mathrm{CV})$ were calculated for each category. $\mathrm{CV}$ is the ratio of standard deviation to mean, which represents the level of variability. Mean canopy height at $1 \mathrm{~cm}$ intervals for each picture was grouped into grazed and conserved grasslands from which we calculated these same descriptive statistics. Area ratio of grass to non-grass was calculated at each $1 \mathrm{~cm}$ interval vertically for every picture.

For the satellite image, besides the descriptive statistics described above, GLCM texture analysis was also run for each optical band and the panchromatic band. Texture analysis was derived from grey level co-occurrence matrix, which describes the average tonal variation of neighbor pixels 
Table 1. Twelve Output Variables from GLCM Texture Analysis through PCI Geomatic (Adapted from PCI Geomatica User'S Manual)

\begin{tabular}{|c|c|c|}
\hline Variable & Formula & Explanation \\
\hline 1. Homogeneity & $\operatorname{SUM}(\mathrm{i}, \mathrm{j}=0, \mathrm{~N}-1)(\mathrm{P}(\mathrm{i}, \mathrm{j}) /(1+(\mathrm{i}-\mathrm{j}) * * 2))$ & $\begin{array}{l}\text { It is high when GLCM concentrates along the diagonal. } \\
\text { This occurs when the image is locally homogeneous in the } \\
\text { scale of the length of spatial. }\end{array}$ \\
\hline 2. Contrast & $\operatorname{SUM}(i, j=0, N-1)(P(i, j) *(i-j) * * 2)$ & $\begin{array}{l}\text { This is the opposite of Homogeneity. It is a measure of the } \\
\text { amount of local variation in the image. It is high when the } \\
\text { local region has a high contrast in the scale of spatial. }\end{array}$ \\
\hline 3. Dissimilarity & $\operatorname{SUM}(i, j=0, N-1)(P(i, j) *|i-j|)$ & $\begin{array}{l}\text { Similar to Contrast. High when the local region has a high } \\
\text { contrast. }\end{array}$ \\
\hline 4. Mean & Mean_i $=\operatorname{SUM}(i, j=0, N-1)(i * P(i, j))$ & Average grey level in the local window. \\
\hline 5. Standard Deviation & $\begin{array}{l}\text { Var_i }=\operatorname{SUM}(i, j=0, N-1)(P(i, j) *(i- \\
\left.\text { Mean_i })^{* * 2}\right) \\
\text { Std. Deviation_i }=\text { SQRT(Var_i })\end{array}$ & $\begin{array}{l}\text { Grey level standard deviation in the local window. High } \\
\text { when there is a large grey level standard deviation in the } \\
\text { local region. }\end{array}$ \\
\hline 6. Entropy & $\begin{array}{l}\operatorname{SUM}(\mathrm{i}, \mathrm{j}=0, \mathrm{~N}-1)(-\mathrm{P}(\mathrm{i}, \mathrm{j}) * \operatorname{LOGe}(\mathrm{P}(\mathrm{i}, \mathrm{j}))) \\
\text { assuming that } 0 * \operatorname{LOG}(0)=0 .\end{array}$ & $\begin{array}{l}\text { It is high when the elements of GLCM have relatively equal } \\
\text { values. Low when the elements are close to either } 0 \text { or } 1 \\
\text { (i.e. when the image is uniform in the window). }\end{array}$ \\
\hline $\begin{array}{l}\text { 7. Angular Second } \\
\text { Moment }\end{array}$ & $\operatorname{SUM}(i, j=0, N-1)(P(i, j) * * 2)$ & $\begin{array}{l}\text { This is the opposite of Entropy. It is high when the GLCM } \\
\text { has few entries of large magnitude, low when all entries are } \\
\text { almost equal. This is a measure of local homogeneity. }\end{array}$ \\
\hline 8. Correlation & $\begin{array}{l}\operatorname{SUM}(i, j=0, N-1)\left(P(i, j) *\left(i-M e a n \_i\right) *\right. \\
\left.\left(j-M e a n \_j\right)\right) / S Q R T\left(V a r \_i * V a r \_j\right)\end{array}$ & $\begin{array}{l}\text { Measures the linear dependency of grey levels of } \\
\text { neighbouring pixels. When the scale of local texture is } \\
\text { much larger than the distance of spatial, correlation is } \\
\text { typically high. When the local texture has a scale similar to } \\
\text { or smaller than spatial, there will be low correlation } \\
\text { between pairs of pixels (apart by spatial). }\end{array}$ \\
\hline $\begin{array}{l}\text { 9. GLDV Angular } \\
\text { Second Moment }\end{array}$ & $\operatorname{SUM}(\mathrm{k}=0, \mathrm{~N}-1)\left(\mathrm{V}(\mathrm{k})^{* *} 2\right)$ & $\begin{array}{l}\text { High when some elements are large and the remaining ones } \\
\text { are small. Similar to Angular Second Moment, it measures } \\
\text { the local homogeneity. }\end{array}$ \\
\hline 10. GLDV Entropy & $\begin{array}{l}\mathrm{SUM}(\mathrm{k}=0, \mathrm{~N}-1)(-\mathrm{V}(\mathrm{k}) * \mathrm{LOGe}(\mathrm{V}(\mathrm{k})) \\
\text { assuming that } 0 * \mathrm{LOGe}(0)=0\end{array}$ & $\begin{array}{l}\text { High when all elements have similar value. This is the } \\
\text { opposite of GLDV Angular Second Moment. }\end{array}$ \\
\hline 11. GLDV Mean & $\operatorname{SUM}(k=0, N-1)(V(k) * k)$ & $\begin{array}{l}\text { It is mathematically equivalent to the Dissimilarity measure } \\
\text { above. }\end{array}$ \\
\hline 12. GLDV Contrast & $\operatorname{SUM}(\mathrm{k}=0, \mathrm{~N}-1)(\mathrm{V}(\mathrm{k}) * \mathrm{k} * * 2)$ & $\begin{array}{l}\text { It is mathematically equivalent to the Contrast measure } \\
\text { above. }\end{array}$ \\
\hline
\end{tabular}

Note: $\mathrm{P}(\mathrm{i}, \mathrm{j})$ is the normalized co-occurrence matrix such that $\mathrm{SUM}(\mathrm{i}, \mathrm{j}=0, \mathrm{~N}-1)(\mathrm{P}(\mathrm{i}, \mathrm{j}))=1 ; \mathrm{V}(\mathrm{k})$ is the normalized grey level difference vector $\mathrm{V}(\mathrm{k})=\operatorname{SUM}(\mathrm{i}, \mathrm{j}=0, \mathrm{~N}-1$ and $|\mathrm{i}-\mathrm{j}|=\mathrm{k}) \mathrm{P}(\mathrm{i}, \mathrm{j})$. 
(Hall-Beyer, 2000). More than one variable can be derived from texture analysis. For example, in PCI Geomatica, the texture analysis output can include as many as 12 variables, which are homogeneity, contrast, dissimilarity, mean, standard deviation, entropy, angular second moment, correlation, GLDV angular second moment, GLDV entropy, GLDV mean, and GLDV contrast (Table 1) (PCI Geometica, 2003).

All variables including the maximum canopy height, mean canopy height, grass to non-grass area ratio, raw digital numbers of the seven bands and variables derived from the texture analysis were compared between grazed and conserved sites. The analysis of variance (ANOVA) test was run for these variables to test if the difference is significant statistically.

\section{Results and Discussion}

\subsection{Vertical Structure of Grazed and Conserved Grass- lands}

\subsubsection{Maximum canopy height}

In comparing the maximum canopy height of each sampling location for grazed and conserved grasslands (Figure 3 and Table 1), conserved grasslands were signifycantly higher than grazed grasslands. The maximum canopy height of conserved grassland reached $89 \mathrm{~cm}$, compared to $70 \mathrm{~cm}$ for grazed sites. The mean maximum height for all samples in conserved sites was $62 \mathrm{~cm}$, compared to $47 \mathrm{~cm}$ for grazed sites. Both the differences were significant at 0.001 level. Standard deviation revealed that the vertical heterogeneity was higher in conserved grasslands than grazed grasslands (14.8 vs. 11.4). The significance of increased canopy height for wildlife derives from the shading effect that influences both the production of the vegetation in the community and its value as habitat for wildlife. Some species prefer tall grass structure such as McCowan's Longspur (McMaster \& Davis 2001) and Sagebrush Vole (T.), while others appear to avoid this habitat such as Mountain Plover (Wershler \& Wallis, 1987) and Richardson's groundsquirrel (Banfield, 1974). Nevertheless, higher maximum canopy height will also provide more diverse vertical structure for wildlife habitats.

\subsubsection{Mean canopy height (algorithm)}

The same conclusion can be drawn for the mean canopy height derived using the $1 \mathrm{~cm}$ spatial interval algorithm (Table 2). The mean canopy height was significantly higher for conserved grassland $(41 \mathrm{~cm})$ than for grazed grassland $(32 \mathrm{~cm})$, as was the standard deviation ( 0.33 vs. 0.30$)$ (at 0.001 significant level). Mean canopy height can be an indicator of biomass because it is the height of majority grasses. This was found in a study conduced by McCanny et al. (1996a) at Grasslands National Park. As their conclusion, biomass was higher for conserved grasslands than that of the grazed grasslands. Therefore, the higher mean canopy height means a higher volume of biomass, which can be a key factor in understanding the distributions of wildlife populations (Davis et al., 1999, Wilmshurst et al., 1999).
Table 2. Statistics Summary for Vertical Structure of Grazed and Conserved Grasslands.

\begin{tabular}{lllll}
\hline $\begin{array}{l}\text { Statistic } \\
\text { Variables }\end{array}$ & \multicolumn{2}{l}{$\begin{array}{l}\text { Maximum Canopy } \\
\text { Height }(\mathrm{cm}) \text { at } \\
\text { sampling level }\end{array}$} & \multicolumn{2}{l}{$\begin{array}{l}\text { Mean Canopy Height } \\
(\mathrm{cm}) \text { at } 1 \mathrm{~cm} \text { interval }\end{array}$} \\
& Grazed & Conserved & Grazed & Conserved \\
\hline Sample size & 72 & 72 & 3032 & 2877 \\
Mean & 47.3 & 62.6 & 32.2 & 41.5 \\
$P$ & 0.000 & & 0.000 & \\
Standard & 11.40 & 14.75 & 9.55 & 13.66 \\
Deviation & & & & \\
CV & 0.24 & 0.24 & 0.30 & 0.33 \\
(std/mean) & & & & \\
Minimum & 24 & 35 & 14 & 20 \\
Maximum & 70 & 89 & 58 & 71 \\
Range & 46 & 54 & 44 & 51 \\
\hline
\end{tabular}

Note: Bold face indicates significance at 0.005 level.

\subsubsection{Grass to non-grass area ratio}

In conserved grasslands, grass to non-grass area ratio began to decline dramatically at $10 \mathrm{~cm}$ above the surface, while the decline began at 3-4 cm for grazed sites (Figure 4). Measured at the same distance above ground, the grass area ratio for grazed grasslands was always lower than conserved grassland (Figure 4). For both grazed and conserved grasslands, the decline of the grass to non-grass area ratio tended to level off at about $32 \mathrm{~cm}$ above the surface. Grass reached much higher canopy height for conserved sites $(78 \mathrm{~cm})$ compared to grazed sites $(53 \mathrm{~cm})$. Therefore, conserved grasslands had higher grass density at any canopy level and also had much higher canopy height. The slower decline in canopy height at conserved sites was mainly caused by the lack of grazing activity by domestic animals such as cattle because the effects of grazing are not only on reducing green vegetation that decrease the canopy height but also on removing dead material that decreases the density. This was also shown by the study conducted by McCanny et al. (1996) with a result of much higher dead materials component of the conserved grasslands. Unfortunately, we were not able to separate green from dead materials in the digital images.

\subsection{Spatial Heterogeneity of Grasslands}

4.2.1 Variability of optical bands for grazed and conserved grasslands

Grazed grasslands showed significantly higher digital numbers of all optical bands than did the conserved grasslands (Table 3). This was caused by the fact that the mixed grass prairie has higher dead material component (Guo et al., submitted). This also complicated the mixed grass prairie study using remote sensing techniques as a typical spectral signature for vegetation is with higher near infrared reflectance and lower red reflectance (Lillesand \& Kiefer, 1994) such as cropland, forest, and grassland with less dead material. 


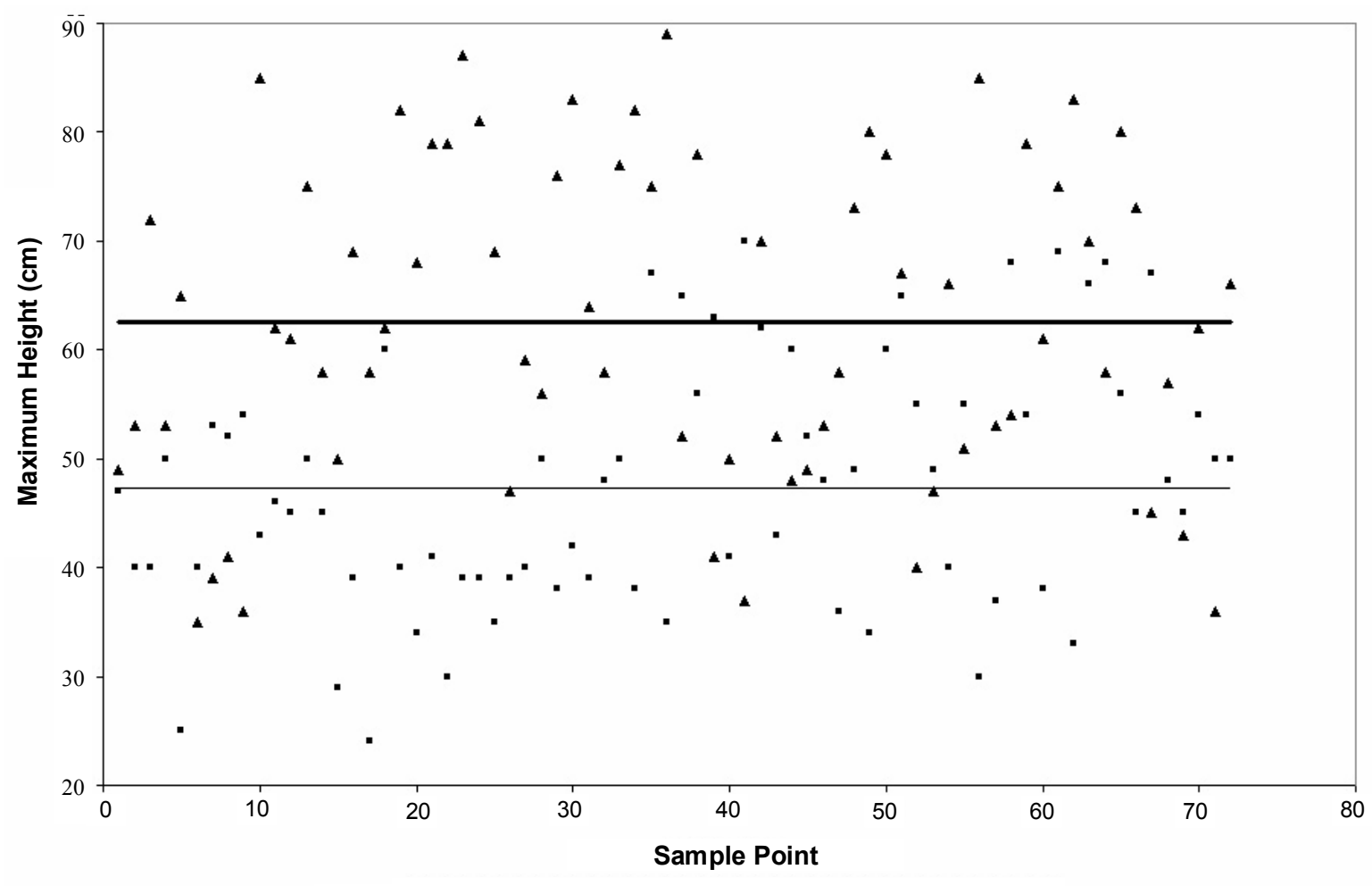

- Grazed ^ Conserved-Grazed Mean-Conserved Mean

Figure 3. Maximum sampling canopy height for grazed and conserved grasslands.

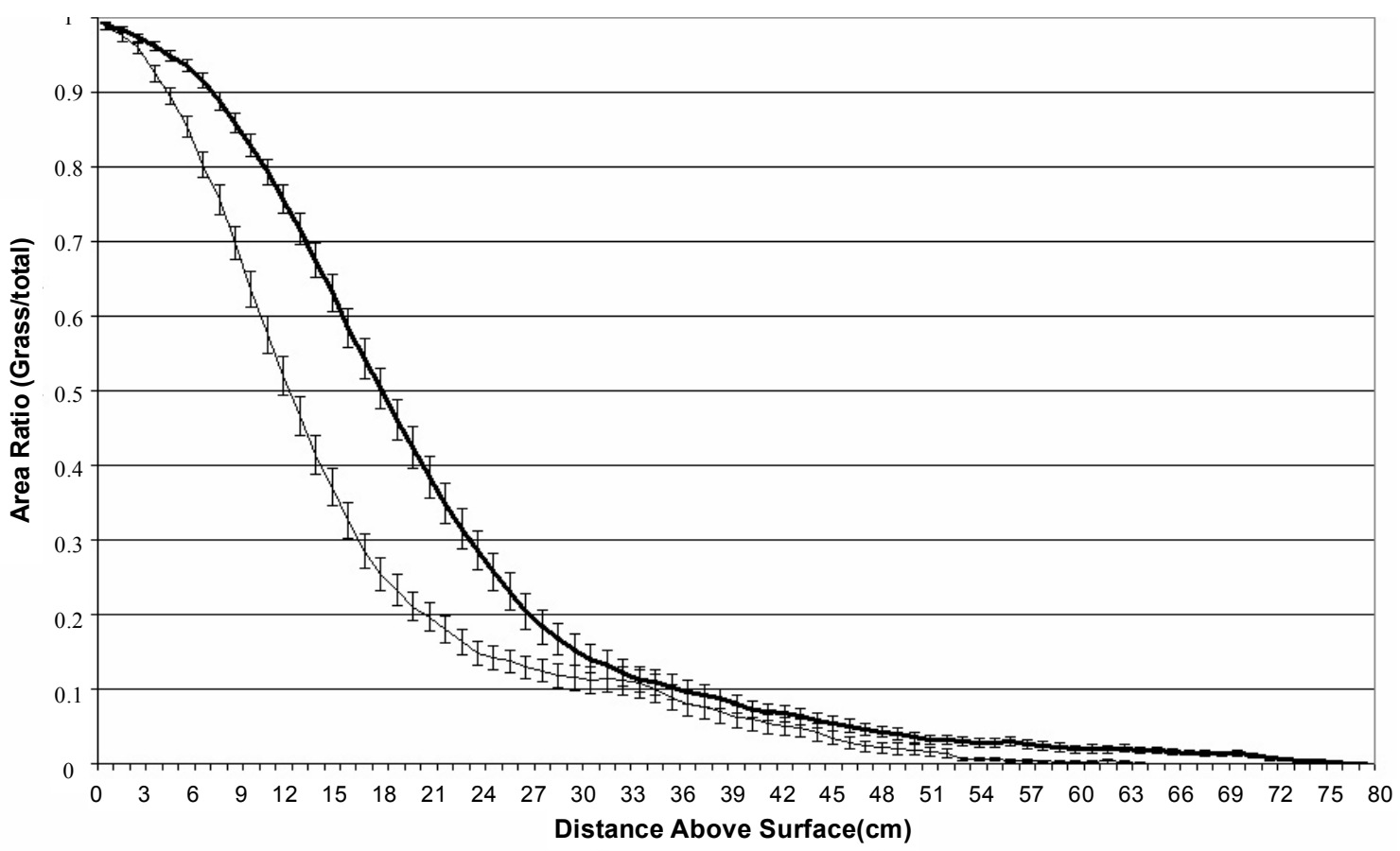

- Grazed-Conserved

Figure 4. Declination lines of grass to non-grass area ratio as increased canopy height for grazed and conserved grasslands with standard error bars. 
Table 3. Statistics Summary for Landsat ETM+ Imagery for the Six Optical Bands Brightness Values of Grazed and Conserved Grasslands.

\begin{tabular}{|c|c|c|c|c|c|c|c|c|c|}
\hline Mgt & Pixels & Variables & $\mathrm{B} 1$ & B2 & B3 & B4 & B5 & B7 & $\mathrm{B} 8$ \\
\hline \multirow[t]{6}{*}{ Grazed } & \multirow[t]{6}{*}{875} & Mean & 76.2 & 61.1 & 65.9 & 78.5 & 117.0 & 75.0 & 49.0 \\
\hline & & Std & 2.71 & 2.52 & 3.60 & 3.99 & 5.09 & 4.11 & 1.66 \\
\hline & & $\mathrm{CV}$ & 0.036 & 0.041 & 0.055 & 0.051 & 0.044 & 0.055 & 0.034 \\
\hline & & Min & 67 & 53 & 54 & 69 & 100 & 61 & 47 \\
\hline & & $\operatorname{Max}$ & 84 & 67 & 77 & 93 & 129 & 85 & 51 \\
\hline & & Range & 17 & 14 & 23 & 24 & 29 & 24 & 4 \\
\hline \multirow[t]{6}{*}{ Conservation } & \multirow[t]{6}{*}{875} & Mean & 74.3 & 58.8 & 62.8 & 73.8 & 111.2 & 70.6 & 46.4 \\
\hline & & Std & 2.35 & 1.98 & 2.77 & 2.85 & 4.22 & 3.84 & 0.90 \\
\hline & & $\mathrm{CV}$ & 0.032 & 0.034 & 0.044 & 0.039 & 0.038 & 0.054 & 0.019 \\
\hline & & Min & 66 & 52 & 53 & 66 & 95 & 54 & 45 \\
\hline & & Max & 81 & 64 & 73 & 83 & 124 & 85 & 48 \\
\hline & & Range & 15 & 12 & 20 & 17 & 29 & 31 & 3 \\
\hline \multicolumn{3}{|c|}{ For mean values: $(P)$} & 0.036 & 0.012 & 0.029 & 0.004 & 0.002 & 0.003 & 0.003 \\
\hline
\end{tabular}

Note: Bold face indicates significance at 0.005 level.

Both standard deviation and CV values were significantly higher in the grazed grasslands than in the conserved grasslands for the seven spectral bands (Table 3) indicating a higher variation in the grazed grasslands than in the conservation grasslands spatially.

Among the seven bands, near infrared, middle infrared bands and the panchromatic band showed higher significant difference compared to other bands between grazed and conserved grasslands (Table 3). This indicates that biomass and moisture content are contributing to the difference at these wavelengths since near infrared wavelength (band 4) is sensitive to biomass, and middle infrared wavelengths (bands 5 and 7) are more sensitive to moisture content (Jensen, 2000), and the panchromatic band with higher spatial resolution which is able to reveal the spatial heterogeneity more precisely.

\subsubsection{Texture analysis}

Among the 12 outputs from the texture analysis, mean was the only variable showed a significant difference between grazed and conservation sites (Figure 5) for 30 meter resolution bands. However, for the panchromatic band, all variables except correlation were significant between the two management practices (Figure 6). This suggests that 30 meter resolution imagery is too coarse for grassland heterogeneity study while 15 meter resolution imagery could provide a promising result. The texture analysis from $15 \mathrm{~m}$ panchromatic band revealed that grazed grasslands had higher spatial heterogeneity than conserved grasslands, perhaps due to the grazing activity. The higher spatial variability among grazed grasslands might be an indicator of a heterogeneous spatial pattern of the grazed grasslands at the scale of 15 metres. A further study of heterogeneity using semivariogram to measure the range, sill and nugget may give a more complete picture al- though Davidson and Csillag (2003b) concluded that the variogram method could not provide an advantage by comparing it with nested analysis of variance method for grassland spatial structure study. However, the higher vertical variability in conserved grasslands, evident in the height measures, was not reflected in the remotely sensed data. From a study by Price et al. (2002) in a tall grass prairie, radar imagery could provide better information on surface structure compared to optical remote sensing. Therefore, radar imagery, with certain penetration ability, may be useful for grassland vertical structure study.

\section{Conclusions}

Results from plot sampling showed a significant difference in vertical heterogeneity between grazed and conserved grasslands. Compared to grazed grasslands, conserved grasslands had higher maximum canopy height and mean canopy height. The standard deviation and CV of canopy height of conserved grasslands were also higher than grazed grasslands. Vegetation was denser for conserved grasslands than grazed sties although live vegetation was not distinguished from dead. However, this vertical heterogeneity did not translate into greater standard deviation at $30 \mathrm{~m}$ resolution in any of Landsat ETM+'s six optical bands and the panchromatic band. Remotely sensed data showed higher standard deviation and CV for grazed than conserved grasslands, which was opposite of the conclusion from the vertical structure analysis. This indicates that the spatial and vertical heterogeneity of grasslands can be influenced differently by grazing and conservation. Grazing appears to increase the spatial heterogeneity while conservation primarily increases the vertical variation. Another conclusion from this study was that 15 meter resolution imagery was better than 30 meter resolution imagery in grassland spatial heterogeneity study. 


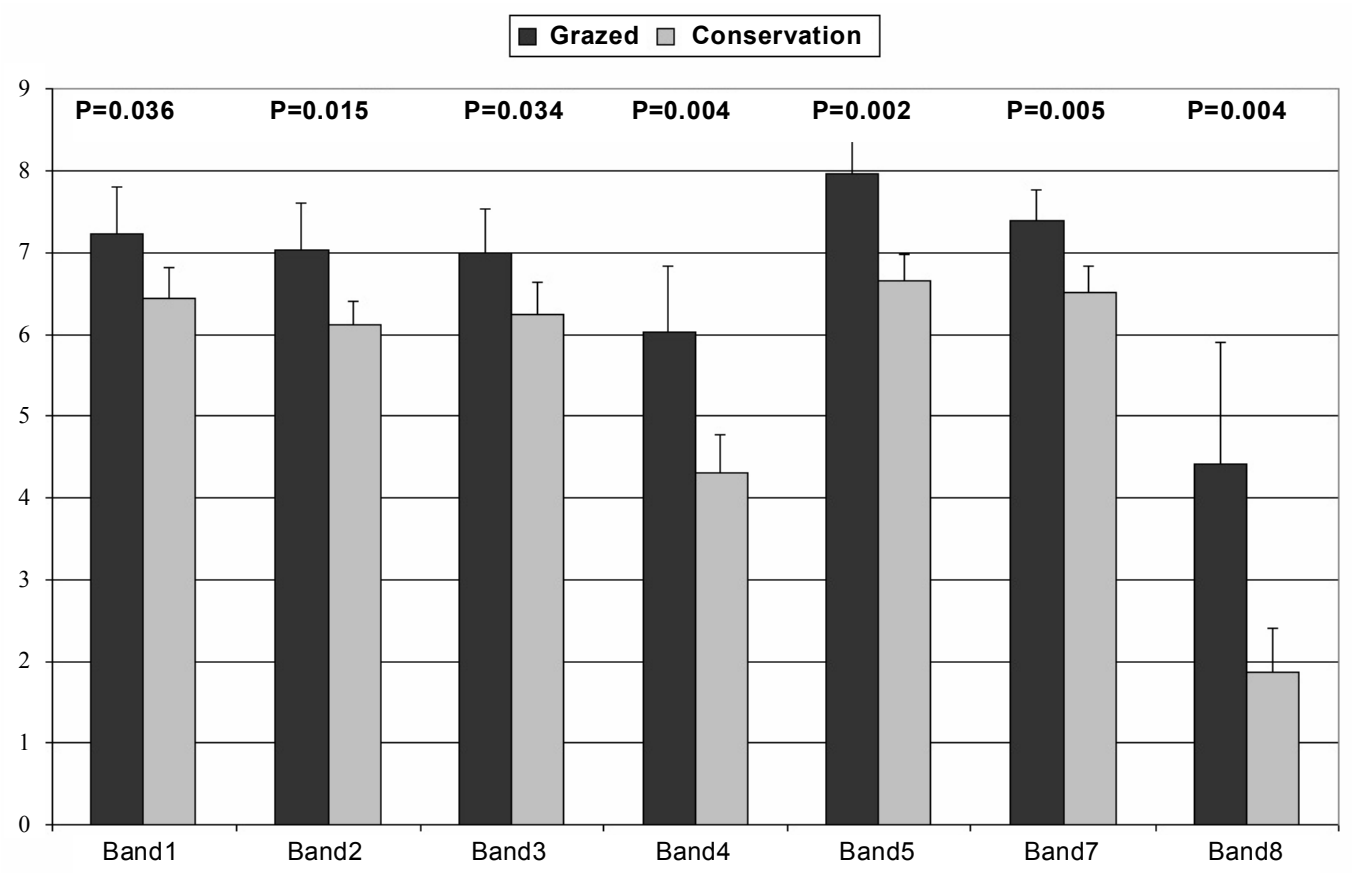

Figure 5. Texture analysis results show the value of texture mean with standard deviation bars for grazed and conservedgrasslands over the six optical bands and the panchromatic band. (The numbers are the significant value for each band between the two managements. Bold face indicates significant at 0.05 level.)

Grazed $\square$ Conservation

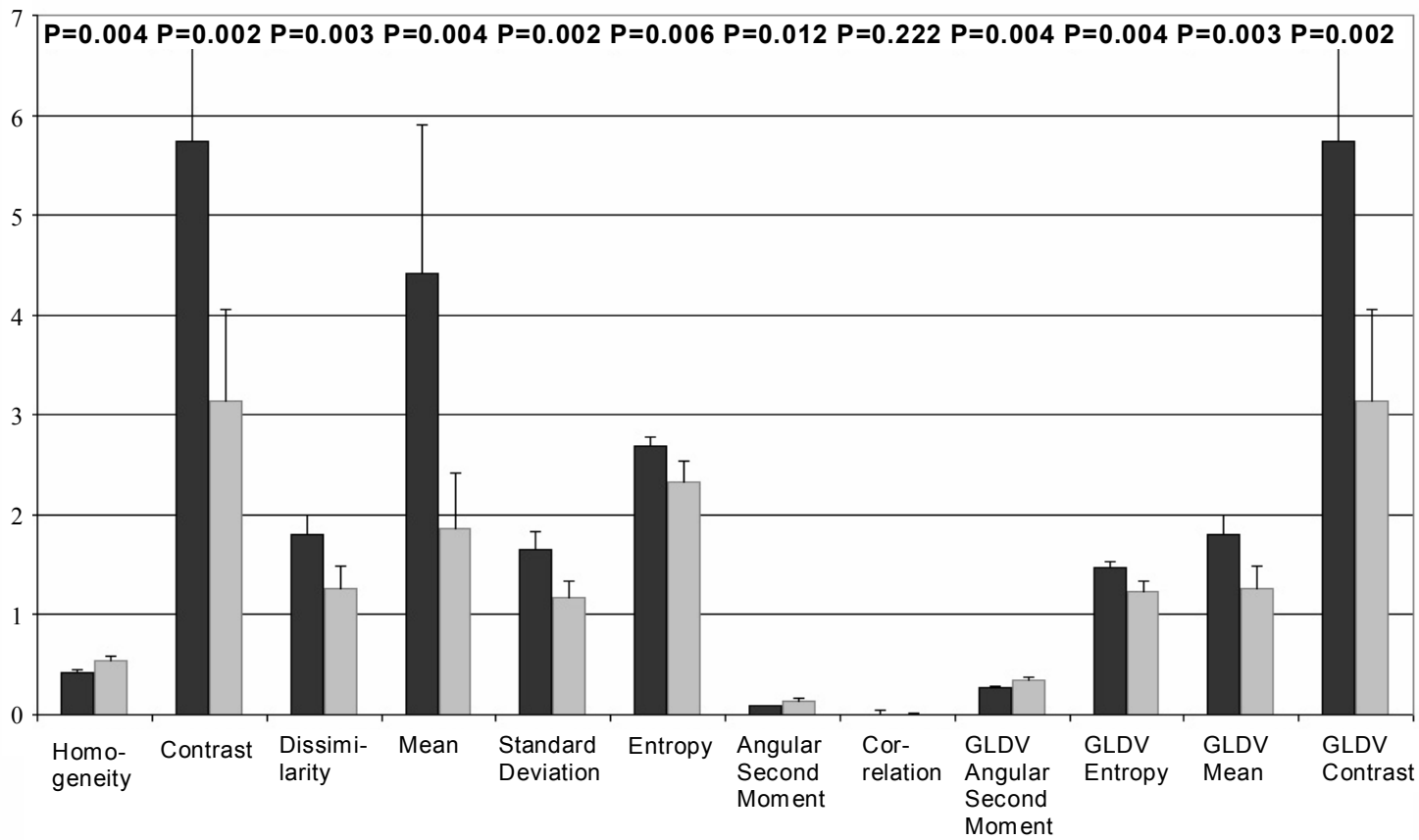

Figure 6. Twelve texture analysis variables from the panchromatic band with standard deviation bars for the grazed and conserved grasslands. (The numbers are the significant value for each variable between the two managements. Bold face indicates significant at 0.05 level.) 
Acknowledgments. This study was supported by the Natural Sciences and Engineering Research Council (NSERC) grant awarded to Dr. Guo and Grasslands National Park of Canada, Parks Canada. Authors would like to thank Mr. Yunpei Lu for the VB code development for digital picture processing.

\section{References}

Adler, P.B., Raff, D.A. and Lauenroth, W.K. (2001). The effect of grazing on the spatial heterogeneity of vegetation. Oecologia, $128,465-479$.

Anys, H. and He, D. (1995). Evaluation of textural and multipolarization radar features for crop classification. IEEE Trans. Geosci. Remote Sens., 33(5), 1170-1181.

Bai, Y., Abouguendia, Z. and Redmann, R.E. (2001). Relationship between plant species diversity and grassland condition. $J$. Range Manage., 54(2), 177-183.

Banfield, A.W.F. (1974). The mammals of Canada, University of Toronto Press, Toronto, Canada.

Briggs, J.M. and Nellis, M.D. (1991). Seasonal variation of heterogeneity in the tallgrass prairie: A quantitative measure using remote sensing. Photogramm. Eng. Remote Sens., 57(4), 407-411.

Cade, T.J. and Woods, C.P. (1997). Changes in distribution and abundance of the Loggerhead Shrike. Conserv. Biol., 11, 21-32.

Collins, S.L. and Steinauer, E.M. (1998). Disturbance, diversity, and species interactions in tallgrass prairie, in A.K. Knapp, J.M. Briggs, D.C. Hartnett and S.L. Collins (Eds.), Grassland Dynamics, Oxford University Press, New York, pp. 40-156.

Davidson, A. and Csillag, F. (2003a). A comparison of three approaches for predicting $\mathrm{C} 4$ species cover of northern mixed grass prairie. Remote Sens. Environ., 86, 70-82.

Davidson, A. and Csillag, F. (2003b). A comparison of nested analysis of variance (ANOVA) and variogram for characterizing grassland spatial structure under a limited sampling budget. Can. J. Remote Sens., 29(1), 43-56.

Davis, S.K. and Duncan, D.C. (1999). Grassland and songbird occurrence in native and crested wheatgrass pastures of southern Saskatchewan. Stud. Avian Biol., 19, 211-218.

Davis, S.K., Duncan, D.C. and Skeel, M. (1999). Distribution and habitat association of three endemic grassland songbirds in southern Saskatchewan. Wilson Bull., 111(3), 390-396.

Desmond, M.J., Savidge, J.A. and Eskridge, K.M. (2000). Correlations between burrowing owl and black-tailed prairie dog declines: A 7-year analysis. J. Wildlife Manage., 64, 1067-1076.

Dennis, P., Roung, M.R. and Gordon, I.J. (1998). Distribution and abundance of small insects and arachnids in relation to structural heterogeneity of grazed, indigenous grasslands. Ecol. Engomology, 23(3), 253-264.

Duffey, E., Morris, M.G., Sheail, J., Ward, L.K., Wells, D.A. and Wells, T.C.E. (1974). Grassland Ecology and Wildlife Management, Chapman and Hall, London.

Environment Canada (2003). Canadian Climate Normals or Averages 1971-2000.

http://www.climate.weatheroffice.ec.gc.ca/climate_normals/index_e.html (accessed Aug 6, 2003).

Gauthier, D.A. and Wiken, E.B. (2003). Monitoring the conservation of grassland habitats, prairie ecozone, Canada. Environ. Monit. Assess., 88, 343-364.

Goodin, D.G. and Henebry, G.M. (1997). A technique for monitoring ecological disturbance in tallgrass prairie using seasonal NDVI trajectories and a discriminant function mixture model. Remote Sens. Environ., 61, 270-278.

Guo, X., Price, K.P. and Stiles, J.M. (2000). Biophysical and spectral characteristics of three land management practices on cool and warm season grasslands in eastern Kansas. Nat. Resour. Res., 9(4), 321-331.

Hall-Beyer, M. (2000). GLCM texture: A tutorial. http://www.ucalgary.ca/ mhallbey/texture/texture_tutorial.html (accessed Mar 8, 2003).

He, D. and Wang, L. (1990). Texture unit, texture spectrum, and texture analysis. IEEE Trans. Geosci. Remote Sens., 28(4), 509-512.

Imhoff, M.L., Sisk, T.D., Milne, A., Morgan, G. and Orr, T. (1997). Remotely sensed indicators of habitat heterogeneity: use of Synthetic Aperture Radar in Mapping Vegetation Structure and Bird Habitat. Remote Sens. Environ., 60, 217-227.

Jakubauskas, M.E. (1997). Effects of forest succession on texture in landsat thematic mapper imagery. Can. J. Remote Sens., 23(3), 257-263.

Jensen, J.R. (2000). Remote Sensing of the Environment: An Earth Resource Perspective, Prentice-Hall, NJ, USA.

Mack, R.N. (1989). Temperate grasslands vulnerable to plant invasions: characteristics and consequences. in J.A. Drake, H.A. Mooney, F.d. Castri, R.H. Groves, F.J. Druger, M. Rejmanak and M. Williamson (Eds.), Biological Invasions: A Global Perspective, Springer, New York, USA, pp. 155-179.

McCanny, S.J., Fargey, P. and Hohn, S. (1996). The effects of grazing and exotic grasses on the ecological integrity of upland prairie. Grasslands Natl. Park Annu. Report, 1, 66-68.

McMaster, D.G. and Davis, S.K. (2001). An evaluation of Canada's permanent cover program: Habitat for grassland birds? J. Field Ornithol., 72, 195-325.

Parks Canada (2002). Grasslands National Park of Canada Management Plan.

PCI Geomatica (2002). User's manual, PCI Geomatic Inc.

Pepper G.W. and Gauthier, D.A. (1998). Saskatchewan Prairie Biodiversity Study.

Price, K.P., Guo, X. and Stiles, J.M. (2002). Comparison of Landsat TM and ERS-2 SAR data for discriminating among six grassland types in eastern Kansas. Comput. Electron. Agric., 37, 157-171.

Roth, R.R. (1976). Spatial heterogeneity and bird species diversity. Ecology, 57, 773-782.

Smeeton, C. and Weagle, K. (2000). The reintroduction of the swift fox vulpes velox to south central saskatchewan, Canada. Oryx, 34, 177-180.

Tilman, D. (1999). Is there time? - Global environmental impacts of agricultural expansion: The need for sustainable and efficient practices, in Proc. of the National Academy of Sciences, pp. 5995-6001.

Wershler, C.R. and Wallis, C.A. (1987). Status Report on the Mountain Plover, Charadrius Montanus, in Canada, Committee on the Status of Endangered Wildlife in Canada.

Wiens, J.A. (1974). Habitat heterogeneity and avian community structure in North American Grasslands. Am. Midl. Nat., 91(1), 195-213.

Wilmshurst, J.F., Fryxell, J.M., Farm, B.P., Sinclair, A.R.E. and Henschel, C.P. (1999). Spatial distribution of Serengeti wildebeest in relation to resources. Can. J. Zool., 77, 1223-1232. 